\title{
A engenharia de usabilidade trabalhando em prol do direito à informação nos sistemas de informações governamentais brasileiros
}

\author{
José Antônio Machado Nascimento \\ Mestre em Ciência da Informação (UnB) \\ Bibliotecário da Agência Nacional de Transportes Aquaviários - ANTAQ
}

\begin{abstract}
Resumo: Verifica a usabilidade dos serviços de informação governamentais através de critérios heurísticos. Discorre sobre a perspectiva histórica das leis de acessibilidade e apresenta conceitos relacionados à acessibilidade na web. Constatou-se que é necessária a revisão da legislação brasileira sobre o assunto e o estudo constante das diretrizes de acessibilidade, pois o papel normativo do Poder Executivo nesse segmento, exercido pelo Ministério do Planejamento, Orçamento e Gestão, só se concretizará mediante a promoção e o estabelecimento de uma gestão empreendedora de recursos para esse fim.
\end{abstract}

Palavras-chave: Acessibilidade; Usabilidade; Direito Público; Serviços de Informação; Governança Eletrônica.

Abstract: This paper verifies the usability of government information services through heuristic criteria. It discusses the historical perspective of accessibility laws and presents concepts related to web accessibility. It was found that it is necessary to revise the Brazilian legislation on the subject and constant study of the accessibility guidelines, because the normative role of the executive branch in this segment, pursued by the Ministry of Planning, Budget and Management, will only be achieved through the promotion and establishment an entrepreneurial management of resources for this purpose.

Key Words: Accessibility, Usability, Public Law, Information services, Electronic Governance.

Resumen: Verifica la usabilidad de los servicios de información gubernamentales a través de criterios heurísticos. Se discute la perspectiva histórica de las leyes de accesibilidad y se presentan conceptos relacionados con la accesibilidad web. Se constató que es necesaria la revisión de la legislación brasileña sobre el asunto y el estudio constante de las directrices de accesibilidad, pues el papel normativo del poder ejecutivo en este segmento, ejercido por el Ministerio de Planificación, Presupuesto y Gestión, sólo se logrará mediante la promoción y el establecimiento una gestión emprendedora de los recursos para este propósito.

Palabras Claves: Accesibilidad, Usabilidad, Derecho Público, Servicios de Información, Gobierno Electrónico. 


\section{Introdução}

O Brasil atingirá, em 2012, a marca de 100 milhões de computadores comercializados (Agência Estado, 2010) e não há como negar o importante papel que os Portadores de Necessidades Especiais (PNE) têm nesse mercado. Afinal, correspondem a 14,5\% da população brasileira, de acordo com dados do censo demográfico de 2000, do Instituto Brasileiro de Geografia e Estatística (IBGE).

De olho nesse segmento, muitas instituições públicas estão facilitando o acesso dos PNEs aos serviços de e-gov, utilizando os benefícios da tecnologia da informação para garantir a esses cidadãos o direito de receber do Estado informações de seu interesse particular, de interesse coletivo ou geral ${ }^{\mathrm{i}}$,i.

Nesse contexto, a Engenharia de Usabilidade, ou simplesmente Usabilidade ${ }^{\mathrm{iii}}$, pode ser uma aliada da Administração Pública no cumprimento das leis de acessibilidade, pois permite o monitoramento de requisitos funcionais fundamentais para que os serviços de informação governamentais sejam considerados satisfatórios.

Esse artigo combina três áreas convergentes - a Engenharia de Usabilidade, o Direito Público e a Ciência da Informação - com o objetivo de verificar, in loco, se os serviços de e-gov orientados ao cidadão, permitem, de fato, acessibilidade aos PNEs.

\section{Perspectiva histórica das leis de acessibilidade}

Segundo VanRanden (2000), os primeiros países a se preocuparem com a acessibilidade na Internet foram o Canadá e a Austrália, em meados de 1997. No entanto, foram os Estados Unidos que aprovaram primeiro uma norma superior a respeito do tema. A famosa Section 508 iv leva em conta o papel primordial da tecnologia como elemento de interferência na inclusão social e no uso prático da informação.

Paralelamente a essas ações que ocorriam na esfera governamental norte-americana, $\mathrm{O} W 3 \mathrm{c}^{\mathrm{v}}$ fomentou a criação do $\mathrm{WAl}^{\mathrm{vi}}{ }^{\text {, }}$, com o intuito de coordenar grupos de trabalho em todo o mundo para garantir o acesso dos PNEs a conteúdos na web.

Os produtos intelectuais do WAI concentraram-se basicamente na elaboração de recomendações para acessibilidade, sendo a primeira delas lançada em 1999, mesmo ano em que Portugal se tornou o quarto país do mundo e o primeiro da Europa a legislar sobre o assunto vii.

No Brasil, somente a partir do ano 2000 começaram a se intensificar os movimentos em prol da causa, mas a regulamentação das leis 10.098/00 e 10.048/00, só viria a ocorrer em dezembro de 2004, com a aprovação do decreto 5296/04 viii. 
A principal inovação nas leis brasileiras foi considerar a acessibilidade um processo dinâmico que perpassa pela tecnologia e sociedade, o que corrobora a observação de Torres et al. (2002, p. 82), que "acessibilidade é um conceito que envolve tanto aspectos do espaço físico, o espaço em que vivemos, como do espaço digital".

Entretanto, as questões relativas ao espaço físico, tais como barreiras de transporte e barreiras urbanísticas têm sido mais discutidas no Brasil dos que os dispositivos legais que referendam a acessibilidade nos serviços de e-gov, conforme nos demonstra as permissões para prorrogações no prazo para que todos os sítios governamentais cumpram as exigências ressaltadas no art.47, do decreto 5296/04 ${ }^{\mathrm{ix}}$.

Recentemente, o Ministério do Planejamento institucionalizou o Modelo de Acessibilidade do Governo Eletrônico, sob a alcunha de e-MAG ${ }^{x}$, no âmbito do Sistema de Administração dos Recursos de Informação e Informática - SISP ${ }^{x i}$. A portaria estabeleceu que

o planejamento, implantação, desenvolvimento e atualização de portais e sítios eletrônicos, sistemas, equipamentos e programas de tecnologias da informação e comunicação - TIC no âmbito da Administração Pública Federal Direta, autáquica e fundacional regerse à por políticas, diretrizes e especificações que visem assegurar de forma progressiva a acessibilidade de serviços e sistemas de governo.

Por ser a verificação dos requisitos de acessibilidade dos diversos serviços de e-gov o propósito desse trabalho, trataremos desse tema mais adiante, mesmo porque para compreendê-lo se faz necessário entender o que vem a ser acessibilidade na web.

\section{Acessibilidade na web}

Segundo Melo et al. (2004, p.165), a "acessibilidade da internet caracteriza-se pela flexibilidade da informação e interação relativa ao respectivo suporte de apresentação". Essa flexibilidade deve permitir a utilização da internet por PNEs em diferentes tipos de aplicações, equipamentos e navegadores.

A acessibilidade na web também não diz respeito ao uso da tecnologia para beneficiar um determinado grupo de pessoas. Significa também fazer uso das tecnologias de informação e comunicação para criar ambientes digitais, conteúdos e funcionalidades compatíveis com todos os tipos de usuários, o que na literatura é denominado "design universal".

O design universal, adotado por diversos web designers e web developers, consiste em igualar as possibilidades de uso, garantindo facilidades na obtenção da informação, mesmo que esse processo se dê intuitivamente. É importante ressaltar que o design universal não alcança apenas os PNEs, mas também usuários de dispositivos móveis, usuários que não 
possuem conexões eficazes à internet, usuários que não possuem equipamentos de áudio, entre outros.

O foco principal dos projetistas de design universal de interfaces é garantir a usabilidade dos sistemas de informação aos PNEs, por intermédio de diversas tecnologias, conforme demonstra o quadro abaixo:

Quadro 1 - Tecnologias assistenciais para incrementar a acessibilidade na web

\begin{tabular}{|c|c|c|}
\hline Tecnologia & O que é & Área de atuação \\
\hline $\begin{array}{l}\text { Leitor de } \\
\text { tela }\end{array}$ & $\begin{array}{l}\text { É um software que lê o texto que está na tela do } \\
\text { microcomputador e a saída desta informação é através } \\
\text { de um sintetizador de voz ou um display Braille. }\end{array}$ & Cegueira. \\
\hline $\begin{array}{l}\text { Navegador } \\
\text { textual }\end{array}$ & $\begin{array}{l}\text { É um navegador baseado em texto, diferente dos } \\
\text { navegadores com interface gráfica onde as imagens são } \\
\text { carregadas. O navegador textual pode ser usado com o } \\
\text { leitor de tela por pessoas cegas e também por pessoas } \\
\text { que acessam a internet com conexão lenta. }\end{array}$ & $\begin{array}{l}\text { Cegueira }- \text { pessoas } \\
\text { que possuem } \\
\text { conexão lenta de } \\
\text { acesso a Internet. }\end{array}$ \\
\hline $\begin{array}{l}\text { Navegador } \\
\text { com voz }\end{array}$ & $\begin{array}{l}\text { É um sistema que permite a navegação orientada pela } \\
\text { voz. Alguns possibilitam o reconhecimento da voz e a } \\
\text { apresentação do conteúdo com sons, outros permitem } \\
\text { acesso baseado em telefone. }\end{array}$ & Cegueira. \\
\hline $\begin{array}{l}\text { Ampliador } \\
\text { de tela }\end{array}$ & $\begin{array}{l}\text { Software que amplia o conteúdo da página para facilitar a } \\
\text { leitura. }\end{array}$ & Baixa visão. \\
\hline $\begin{array}{l}\text { Distinção } \\
\text { de cores } \\
\text { no } \\
\text { website }\end{array}$ & $\begin{array}{l}\text { Personalização das cores, de acordo com regras de } \\
\text { usabilidade. }\end{array}$ & Daltonismo. \\
\hline Legendas & Personalização do conteúdo do website. & Deficiência auditiva. \\
\hline $\begin{array}{l}\text { Teclado } \\
\text { alternativo }\end{array}$ & $\begin{array}{l}\text { Dispositivo de hardware ou software que pode ser usado } \\
\text { por pessoas com deficiência física, que fornece um modo } \\
\text { alternativo de dispor as teclas como, por exemplo, } \\
\text { teclado com espaçamentos maiores ou menores entre as } \\
\text { teclas. }\end{array}$ & Deficiência física. \\
\hline
\end{tabular}

Fonte: SERPRO - http://www.serpro.gov.br/acessibilidade/acesso.php 
Para atingir o "estado da arte" no que concerne a elaboração de interfaces web com essas tecnologias, diversas metodologias têm sido propostas e utilizadas para determinar até que ponto os serviços de e-gov estão adequados em relação à acessibilidade. Alguns desses métodos são: uso de navegadores gráficos e textuais, validação automática da linguagem de marcação, verificação de acessibilidade por ferramentas semi-automáticas e avaliação com usuários com diferentes habilidades e deficiências (TORRES et al., 2004, p. 166).

Contudo, salienta-se que caso esses métodos não estejam adequados ao seu contexto de uso, todo o processo de verificação da acessibilidade será prejudicado em função do desconhecimento das necessidades do usuário, já que não são encontrados na literatura "métodos específicos que contemplem usuários com deficiências" (TORRES et al., 2004, p. 166).

Passamos agora a explicação detalhada da metodologia utilizada para a verificação de requisitos de acessibilidade nos serviços brasileiros de $e$-gov.

\section{Metodologia}

Para a consecução desse trabalho, partiu-se da premissa que não existe uma metodologia de usabilidade específica para a avaliação de serviços de informação governamentais. Por isso, adotou-se para a validação e verificação dos dados características de estudo de caso, que funcionam como uma "análise intensiva de uma situação particular" (TULL, 1976, p. 3).

Embora existam várias metodologias de avaliação de usabilidade e acessibilidade propostas por diversos pesquisadores (NIELSEN, 1993, 1994, 2000; DIAS, 2001; CYBIS, 2004), optou-se pela adaptação ao contexto dessa pesquisa dos critérios de acessibilidade desenvolvidos por LAUX et al. (1996), que refletem a especificidade do direito à informação de forma associativa.

Elaborou-se então, uma avaliação baseada em critérios heurísticos, já que o objetivo do trabalho não foi verificar os objetos de interação das interfaces, o que seria incompatível com o tempo estabelecido para a realização da pesquisa.

A seguir, são apresentados os critérios heurísticos de acessibilidade definidos:

1. O conteúdo disponível no website é compatível com tecnologias assistenciais?

2. Os usuários controlam e entendem restrições de tempo?

3. Textos alternativos são disponibilizados para descrever os elementos textuais?

4. A navegação é consistente e corretamente rotulada?

5. O sistema de informação permite o uso completo e eficiente do teclado?

6. As propriedades dos navegadores são respeitadas? 
7. Elementos como formulários são utilizados adequadamente?

8. Os usuários controlam distrações em potencial?

9. As informações são apenas associadas a cores?

Findada a elaboração dos instrumentos de coleta de dados, foi definido o universo da pesquisa. A princípio, pensou-se em utilizar uma gama de serviços que representassem as seguintes áreas de atuação: agricultura e pecuária, assistência e previdência social, ciência e tecnologia, cultura, economia, educação, esporte e saúde. Mas, seria necessário ter acesso às estatísticas coletadas pelo SERPRO para tal propósito.

Como demandaria tempo a autorização para o acesso a esses documentos, a melhor opção foi a adoção da lista dos serviços de e-gov mais procurados, disponíveis no site www.brasil.gov.br, como amostra significativa do universo da pesquisa, a saber:

1. Aposentadoria por idade - Ministério da Previdência Social;

2. Andamento de processos de concessão de benefícios - Ministério da Previdência Social;

3. Consulta - situação cadastral de pessoa física - CPF - Ministério da Fazenda/Receita Federal;

4. Aposentadoria especial - Ministério da Previdência Social;

5. Andamento de processos de revisão de benefícios - Ministério da Previdência Social;

6. Auxílio-doença - Ministério da Previdência Social;

7. Bulário eletrônico - Agência Nacional de Vigilância Sanitária;

8. Concursos - Ministério do Planejamento, Orçamento e Gestão;

9. Direito ao Pré-Natal - Ministério da Saúde;

10. Aposentadoria por invalidez - Ministério da Previdência Social.

Todos os serviços de e-gov que compõem o universo da pesquisa foram avaliados por dois especialistas em usabilidade e acessibilidade, pois somente especialistas detêm o conhecimento que permite a aplicação das técnicas de maneira correta, poupando tempo e garantindo resultados mais confiáveis. Segundo Reitz et al. (2004) é "indispensável que os avaliadores sejam especialistas em ergonomia, para que não haja perda de tempo na busca por conhecimento ergonômico e técnico dos componentes de interação de uma interface".

\section{Resultados}

Os resultados são apresentados de acordo com os critérios heurísticos. Essa medida foi tomada visando facilitar a compreensão dos problemas de usabilidade. 


\section{1 - Conteúdo x tecnologias assistenciais}

Os conteúdos dos serviços selecionados para a avaliação, assim como seus respectivos mecanismos de busca e elementos de interação, apresentam conexões com as tecnologias assistenciais.

Os serviços "aposentadoria por idade", "aposentadoria especial", "auxílio-doença" e "aposentadoria por invalidez" apenas esclarecem informações a respeito dos benefícios, não caracterizando uma facilidade para os PNEs usuários do e-gov, pois não substituem a visita a uma agência do INSS para maiores esclarecimentos.

Os serviços "andamento de processos de concessão inicial de benefícios", "consulta a situação cadastral - CPF", "andamento de processos de revisão de benefícios", "bulário eletrônico" e "concursos" disponibilizam mecanismos de busca que eliminam a possibilidade de visitas aos órgãos responsáveis, o que contribui para a desburocratização do serviço e o uso e divulgação da certificação digital de documentos, conforme orientações estabelecidas pelas autoridades certificadoras brasileiras.

\section{2 - Controle do usuário $x$ restrições de tempo}

Em todos os serviços analisados o usuário controla as restrições de tempo, ou seja, ele só é desconectado mediante sua vontade. Todavia, os mecanismos de busca dos serviços "andamento de processos de revisão de benefícios", "bulário eletrônico" e "consulta a situação cadastral - CPF" possuem restrições relativas à busca por formulários.

Dessa maneira, caberá ao usuário tirar maior proveito das funcionalidades, pois não são ofertados manuais de auxílio ou instruções de uso, o que os leva a cometer erros ou ter que reenviar as informações.

\section{3 - Textos alternativos $\mathrm{x}$ elementos textuais tradicionais}

Os avaliadores atestaram que à exceção do bulário eletrônico da Agência Nacional de Vigilância Sanitária, todos os serviços avaliados não fazem uso da criatividade para facilitar o acesso aos PNEs, pois a leitura das imagens é a mesma dos textos dos links.

\section{4 - Navegação x rotulagem}

De modo geral, os serviços apresentam uma arquitetura da informação equilibrada. Contudo, esse equilíbrio não é visível nos serviços "andamento de processos de concessão inicial de benefícios", "consulta a situação cadastral - CPF" e "andamento de processos de revisão de benefícios", pois são mais facilmente acessados do sítio www.brasil.gov.br que das homepages dos órgãos responsáveis. Esse problema demonstra a necessidade de maior 
interação entre os produtores de conteúdo dos serviços e os responsáveis pelo Portal do Governo Brasileiro, sob responsabilidade da Secretaria de Comunicação (SECOM), da Presidência da República.

\section{5 - Uso completo e eficiente do teclado}

Todos os serviços foram aprovados nesse quesito, provando que os critérios de acessibilidade relativos ao uso dos teclados são respeitados pelos desenvolvedores e projetistas web, que atuam no âmbito do governo federal. As tags de acessibilidade mais utilizadas para garantir o uso eficiente do teclado são: "alt" para descrição das funções e "map" para as regiões clicáveis dos textos.

\section{6 - Propriedade dos navegadores}

A eficácia dos navegadores foi verificada nos seguintes serviços: "andamento de processos de concessão inicial de benefícios", "consulta a situação cadastral de pessoal física CPF", "andamento de processos de revisão de benefícios" e "bulário eletrônico".

Em todos os serviços, os objetos e elementos gráficos das páginas possuem áreas programadas que direcionam os usuários aos bancos de dados, por intermédio dos pontos de acesso.

Todavia, os avaliadores salientaram que durante o uso dos leitores de tela não foi possível acessar todas as funcionalidades desses serviços, levando a crer que pode ser necessária uma reformulação em seus respectivos sistemas de navegação.

\section{7 - Adequação dos formulários}

Os serviços que foram avaliados de acordo com as propriedades dos navegadores também foram avaliados de acordo com a adequação dos formulários. Em todos, os aplicativos são corretamente exibidos, mas os avaliadores observaram que não é possível o preenchimento dos formulários por aqueles que possuem deficiência visual, já que essa funcionalidade depende do estabelecimento correto das propriedades dos navegadores.

\section{8 - Controle de distrações pelos usuários}

Em nenhum dos serviços avaliados foram encontrados sistemas de alerta. Entretanto, os avaliadores notaram que ao utilizarem leitores de tela, todos os serviços provocaram intermitência dos computadores reservados para a avaliação. 


\section{9 - Associação de cores às informações}

As informações veiculadas nos serviços também estão disponíveis sem cor, fazendo uso do próprio contexto ou de marcações. Também foi constatado que os documentos que compõem as bases de dados podem ser lidos sem o recurso folha de estilo, já que são produzidos apenas na linguagem de marcação HTML - hypertext markup language.

\section{Considerações Finais}

É do conhecimento de todos que os PNEs passam por inúmeras dificuldades no seu dia-a-dia, sendo dever do Estado garantir sua inclusão social, independentemente dos rumos que a humanidade segue, seja por meio de novas tecnologias ou através da evolução do conhecimento.

Nesse trabalho, que objetivou verificar se os serviços de e-gov prestados pela Administração Pública Federal permitem, de fato, acessibilidade aos PNEs, ficou comprovado que muito ainda precisa ser feito para o alcance da excelência em termos de qualidade nesse quesito.

O primeiro passo nesse sentido é fazer com que as tecnologias assistivas alcancem todos os brasileiros, em qualquer lugar, em qualquer momento, pois "uma rede de informações tão completa quanto a internet aumenta a necessidade por acessibilidade (LAUX et al, 1996, citado por Souza, 2005)".

É relevante também a revisão da legislação brasileira sobre acessibilidade, já que uma parcela das normas vigentes que disciplinam os serviços de e-gov atuam apenas no âmbito das recomendações. Enquanto a legislação permitir prorrogações para a adaptação ou reformulação dos serviços, mais demora por parte do poder público ocorrerá, já que é notório por parte do governo federal o descaso quanto à contratação de empregados qualificados na área de acessibilidade, pois as vagas disponíveis para analistas de informática e bibliotecários nos diversos concursos realizados nos últimos anos não contemplam profissionais com especialização nessa área.

Por fim, o papel normativo do Poder Executivo, exercido pelo Ministério do Planejamento, Orçamento e Gestão, em relação a acessibilidade só se concretizará mediante a promoção e o estabelecimento de uma gestão empreendedora de recursos para esse fim. Dessa forma, a Internet brasileira se tornará ainda mais democrática, congregando tecnologia e imaginação na direção do bem-estar de todos (SOUZA, 2005). 


\section{Referências Bibliográficas}

Agência Estado. Número de computadores no Brasil deve duplicar até 2010. Disponível em: $<$ http://noticias.r7.com/tecnologia-e-ciencia/noticias/numero-de-computadores-no-brasildeve-duplicar-ate-2014-20100415.html >. Acesso em 16 abr. 2010.

BRASIL. Constituição (1988). Título II (Dos direitos e garantias fundamentais), Cap. I (Dos direitos e deveres individuais coletivos), art. 5ㅇ, XXIII. Brasília: Subsecretaria de Edições Técnicas do Senado Federal, p. 15. 2007.

BRASIL. Decreto no 5296, de 2 de dezembro de 2004. Base da Legislação Federal do Brasil. Disponível em: <https://www.planalto.gov.br/ccivil_03/_Ato20042006/2004/Decreto/D5296.htm>. Acesso em: 4 nov. 2009.

BRASIL. Lei no 10.048, de 8 de novembro de 2000. Base da Legislação Federal do Brasil. Disponível em: <http://www.planalto.gov.br/ccivil_03/Leis/L10048.htm>. Acesso em: 4 nov. 2009.

BRASIL. Lei no 10.098, de 19 de dezembro de 2000. Base da Legislação Federal do Brasil. Disponível em: < http://www.planalto.gov.br/ccivil_03/Leis/L10098.htm>. Acesso em: 4 nov. 2009.

BRASIL. Ministério do Planejamento, Orçamento e Gestão. Portaria no 3, de 7 de maio de 2007. Disponível em: <www.mpog.gov.br>. Acesso em: 15 nov. 2009.

BRASIL.GOV.BR. Serviços mais procurados. Presidência da República. Disponível em: < http://www.brasil.gov.br/servicos/>. Acesso em: 16 nov. 2009.

CARPANEZ, Juliana. Metade dos brasileiros nunca usou computador. Folha Online, São Paulo, 24 nov. 2005. Disponível em:

<http://www1.folha.uol.com.br/folha/informatica/ult124u19297.shtml>. Acesso em: 24 out. 2009.

CYBIS, Walter de Abreu. Engenharia de usabilidade: uma abordagem ergonômica. Disponível em:

<http:www.labutil.inf.ufsc.br/apostila_nvVersao.pdf>. Acesso em: 10 maio 2004.

DIAS, Claudia Augusto. Métodos de avaliação de usabilidade no contexto de portais corporativos: um estudo de caso no Senado Federal. 2001. 229 f. Dissertação (Mestrado) Curso de Ciência da Informação e Documentação, Departamento de Ciência da Informação e Documentação, UnB, Brasília, 2001.

Disponível em:

<http://www.cinted.ufrgs.br/renote/nov2004/artigos/a4_abordagem_ergonomica.pdf>. Acesso em: 28 abr. 2010.

ESTADOS UNIDOS. Section 508, 1998. Disponível em: < http://www.section508.gov/index.cfm?FuseAction=Content\&ID=3>. Acesso em: 15 nov. 2009.

IBGE. Censo Demográfico 2000. Rio de Janeiro: IBGE, 2002. 
LAUX, Lila F.; MCNALLY, Peter R.; PACIELLO, Michael G.; VANDERHEIDEN, Gregg C. Designing the World Wide Web for People with Disabilities: A User Centered Design Approach. British Columbia: ACM, 1996.

MELO, Amanda Meincke; BARANAUSKAS, M. Cecília M; BONILHA, Fabiana Fator Gouvêa. Avaliação de Acessibilidade na Web com a Participação do Usuário - um Estudo de Caso. In: SIMPÓSIO SOBRE FATORES HUMANOS EM SISTEMAS COMPUTACIONAIS, 6, 2003, Curitiba. Anais... Rio de Janeiro, 2004, p. 165-169.

NASCIMENTO, José Antonio Machado do. Usabilidade no contexto de gestores, desenvolvedores e usuários do website da Biblioteca Central da Universidade de Brasília. Brasília, Universidade de Brasília - UNB, Departamento de Ciência da Informação.

NIELSEN, Jakob. How to conduct an heuristic evaluation. In: NIELSEN, Jakob; MACK, Robert. Usability inspection methods. New York: John Wiley \& Sons, 1994. Cap. 2, p. 27-36.

NIELSEN, Jakob. Projetando websites. São Paulo: Campus, 2000. 416 p.

NIELSEN, Jakob. Usability engineering. Boston: Academic Press Professional, 1993. 362 p.

PADDISON, C.; ENGLEFIELD, P. Applying heuristics to perform a rigorous Accessibility inspection in a commercial context. Disponível em:

<http://portal.acm.org/citation.cfm?id=957205.957228i>. Acesso em: 19 nov. 2009.

PORTUGAL. Presidência do Conselho de Ministros. Resolução no 197, de 8 de junho de 1999. Disponível em: <www.acessibilidade.gov.pt>. Acesso em: 4 nov. 2009.

REITZ, Doris Simone; AMARAL, Fernando Gonçalves do; CYBIS, Walter de Abreu. Abordagem Ergonômica de Avaliação de Websites no âmbito da Educação à Distância. Novas Tecnologias Na Educação, Porto Alegre, v. 2, n. 2, 2004.

SOUZA, Edson Rufino. Avaliação de web site baseada em critérios heurísticos de acessibilidade. In: SEMINÁRIO ACESSIBILIDADE, TI E INCLUSÃO DIGITAL, 2, 2005, São Paulo. Anais eletrônicos...São Paulo: Universidade de São Paulo, Faculdade de Saúde Pública. Disponível em: $<$

http://hygeia.fsp.usp.br/acessibilidade/cd2005/conteudo/ATIID2005/MR2/02/AvaliacaoWebSi te.pdf>. Acesso em: 2 nov. 2009.

TORRES, Elisabeth Fátima Torres; MAZZONI, Alberto Angel; ALVES, João Bosco da Mota. A acessibilidade à informação no espaço digital. Ciência da Informação, Brasília, v. 31, n. 3, p. 8391, set./dez. 2002.

TULL, Donald S. Marketing research, meaning, measurement and method. London: Macmillan Publishing Co., 1976.

VANRANDEN, Michael. A brief history of web accessibility intiatives and laws. Suite101.com, Florida, aug. 2000. Disponível em: <http://www.suite101.com/profile.cfm/pegglegg>. Acesso em: 1 nov. 2007.

8. Anexo - Relação dos endereços eletrônicos dos serviços avaliados, de acordo com a lista dos serviços mais procurados do Portal do Governo Brasileiro - www.brasil.gov.br:

1. Aposentadoria por idade - Ministério da Previdência Social: 
http://www.previdencia.gov.br/pg secundarias/beneficios 02.asp

2. Andamento de processos de concessão de benefícios - Ministério da Previdência Social: http://www010.dataprev.gov.br/cws/contexto/consit/consit1.html

3. Consulta - situação cadastral de pessoa física - CPF - Ministério da Fazenda/Receita

Federal:

http://www.receita.fazenda.gov.br/Aplicacoes/ATCTA/CPF/ConsultaPublica.asp

4. Aposentadoria especial - Ministério da Previdência Social:

http://www.previdencia.gov.br/pg secundarias/beneficios 05.asp

5. Andamento de processos de revisão de benefícios - Ministério da Previdência Social: http://www010.dataprev.gov.br/cws/contexto/consit02/index.html

6. Auxílio-doença - Ministério da Previdência Social:

http://www.previdencia.gov.br/pg secundarias/beneficios 06.asp

7. Bulário eletrônico - Agência Nacional de Vigilância Sanitária:

http://www.anvisa.gov.br/medicamentos/bulas/index.htm

8. Concursos - Ministério do Planejamento, Orçamento e Gestão:

http://www.servidor.gov.br/concursos/index.htm

9. Direito ao Pré-Natal - Ministério da Saúde:

http://portal.saude.gov.br/portal/saude/cidadao/area.cfm?id area=152

10. Aposentadoria por invalidez - Ministério da Previdência Social

http://www.previdencia.gov.br/pg secundarias/beneficios 03.asp

Notas

' Constituição da República Federativa do Brasil de 1988, Titulo II (Dos direitos e garantias fundamentais), Capítulo I (Dos direitos e deveres individuais coletivos), art. 50, XXXIII.

ii Constituição da República Federativa do Brasil de 1988, Titulo II (Dos direitos e garantias fundamentais), Capítulo I (Dos direitos e deveres individuais coletivos), art. 5ㅇ, XXXIII.

\begin{abstract}
iii Consolidada como área de estudo interdisciplinar na comunidade científica mundial, a partir da década de 1970, a Ergonomia contribuiu para o desenvolvimento de sistemas interativos, que ocorreram paralelamente ao estabelecimento de redes eletrônicas. Para reduzir custos de produção e manutenção, ergonomistas passaram a criar novas metodologias que identificassem problemas relativos ao contexto de uso dos sistemas. Esse conjunto de métodos e técnicas estruturadas passou a ser conhecido como Engenharia de Usabilidade ou simplesmente Usabilidade (NASCIMENTO, 2006), definida como "a extensão em que um produto pode ser usado por usuários específicos para alcançar objetivos específicos como efetividade, eficácia e satisfação num contexto específico de uso" (ISO 9241, 1996).
\end{abstract}

${ }^{i v}$ Lei norte-americana que estabelece que a tecnologia eletrônica e de informação dos órgãos federais seja acessível às pessoas portadoras de deficiência.

${ }^{\vee}$ W3c - World Wide Web Consortium - Comitê formado por grandes empresas que atuam na web com o objetiva de potencalizar ao máximo a interoperabilidade da rede.

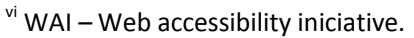

vii Decreto-lei 197/99 - Portugal.

viii Decreto 5296/04, Cap. III (das condições gerais da acessiblidade):

Art. $8^{\circ}$ Para os fins de acessibilidade, considera-se:

I-acessibilidade: condição para utilização, com segurança e autonomia, total ou assistida, dos espaços, mobiliários e equipamentos urbanos, das edificações, dos serviços de transporte e dos dispositivos, sistemas e meios de comunicação e informação, por pessoa portadora de deficiência ou com mobilidade reduzida;

${ }^{\text {ix }}$ Art. 47. No prazo de até doze meses a contar da data de publicação deste Decreto, será obrigatória a acessibilidade nos portais e sítios eletrônicos da administração pública na rede mundial de computadores (internet), para o uso das pessoas portadoras de deficiência visual, garantindo-lhes o pleno acesso às informações disponíveis

× O Modelo de Acessibilidade do Governo Eletrônico apresenta recomendações acessibilidade para a construção ou adaptação de conteúdos do governo brasileiro na Internet.

${ }^{x i}$ Portaria no 3, de 7 de maio de 2007. 